\title{
No dose adjustment of tigecycline is necessary during continuous renal replacement therapy: we are not sure
}

\author{
Patrick M. Honore*, Cristina David, Luc Kugener, Sebastien Redant, Rachid Attou, Andrea Gallerani and \\ David De Bels
}

Broeker et al. conclude that tigecycline (TGC) losses during continuous renal replacement therapy (CRRT) are comparable to those of patients with normal renal function, indicating that no dose adjustment of TGC is necessary during CRRT [1]. We would like to make some comments. First, the RRT modality chosen may have influenced TGC elimination. TGC clearance during continuous veno-venous hemodiafiltration (CVVHDF) was more efficient $(2.71 \mathrm{~L} / \mathrm{h})$ as compared to continuous veno-venous hemodialysis $(C V V H D)(1.69 \mathrm{~L} / \mathrm{h})$ [1]. Second, Broeker et al. attribute the increased clearance of TGC with CVVHDF to low plasma protein binding ( $\mathrm{u}$ recently reported as $50-70 \%$, compared to the previously reported 11-29\%) [1], allowing better elimination through ultrafiltration [1]. This increased ultrafiltration yields a saturation coefficient of 0.79 for CVVHD and 0.90 for CVVHDF and probably higher for CVVH [1]. The removal by CVVHDF and CVVHD yield together a value of $11.2 \%$ [1]. If we look at CVVHD alone $(1.69 \mathrm{~L} / \mathrm{h})$, this represents only $9 \%$ of the total body clearance $(18.3 \mathrm{~L} / \mathrm{h})$ [1]. Looking at CVVHDF $(2.71 \mathrm{~L} / \mathrm{h})$, this represents almost $15 \%$. Third, TGC protein binding is affected by divalent cations such as calcium, and accordingly, regional citrate anticoagulation (RCA) might affect membrane transfer [1]. This would be suspected if convection was used in the study as it is more protein binding dependent. RCA was only used in CVVHD and not in CVVHDF, where unfractionated heparin (UHF) was used $[1,2]$. Fourth, TGC can be adsorbed by plastic labware [3] and there is a great suspicion that TGC could be adsorbed by highly adsorptive membranes (HAM) [4]. Broeker et al. used a polysulfone membrane which is poorly adsorptive [3]; nevertheless, in their study, they observed a time delay in the effluent concentrations in

\footnotetext{
* Correspondence: Patrick.Honore@CHU-Brugmann.be

This comment refers to the article available at https://doi.org/10.1186/ s13054-018-2278-4

ICU Department, Centre Hospitalier Universitaire Brugmann, Place Van Gehuchtenplein, 4, 1020 Brussels, Belgium
}

one patient that may have been caused by adsorption losses inside the membrane [1]. They concluded that since the delay indicated a saturable binding, adsorption losses did not impact the dialysis clearance significantly [1]. We respectfully disagree, as most of the adsorption of small molecules does not occur at the surface of the membrane but rather occurs inside the membrane fibers and therefore it takes more time to become saturated [5]. Indeed, Tian et al. clearly demonstrated that the absence of saturation could exclude surface adsorption, as repeated doses of amikacin resulted in further bulk adsorption [5]. Overall, the conclusion that no dose adjustment is necessary during CRRT seems somewhat premature.

\section{Authors' response}

A. Broeker, C. Dorn, A. Kratzer, F. Kees, A. Heininger, M.G. Kees, H. Häberle, S.G. Wicha

We appreciate the comments by Honore et al. on our article [1]. We agree that with the data at hand, we cannot extrapolate to other RRT settings and membrane types than the ones investigated in our study. In fact, these points were stated by us as limitation of the study [1].

It is correct that RRT clearance was estimated to approx. $11.2 \%$ of the body clearance of tigecycline [1]. The mass balance analysis was presented including 10th-90th percentiles to indicate the variability in this vulnerable population. This in mind, we want to emphasize that even the 90th percentile evaluated (18.3\% of the total elimination via CRRT) in patients suffering from acute kidney injury would not differ in a clinically relevant extent from the renal clearance $(13 \%$ of the total elimination via renal elimination (SPC Tygacil $50 \mathrm{mg}$ powder for solution for infusion, Pfizer Limited, Sandwich, UK) of non-renally impaired subjects).

Our study investigated two different RRT types (CVVHD and CVVHDF), but we were cautious to draw strong conclusions about differences between these two modes, given 
the modest differences observed and the small sample size. The speculation on the role of the anticoagulant used and its effect on protein binding is certainly a perspective for future research.

We agree with Honore et al. that adsorption is an underappreciated phenomenon in RRT clearance and requests deeper investigation as also stated in the limitations [1]. In vitro adsorption of tigecycline to polysulphone membranes was investigated by Sevillano et al. [6] where no issues regarding adsorptive loss were found in protein-containing medium (Mueller-Hinton broth) supporting our findings. Moreover, in our study [1], the post-filter plasma concentrations were collected but not used in the original analysis. In the patient where a delay was observed, a stable saturation coefficient $\left(\left(c_{\text {pre-filter }}-\right.\right.$ $\left.\left.c_{\text {post-filter }}\right) / c_{\text {pre-filter }}\right)$ over time $\left(t_{1 \mathrm{~h}}=0.520, t_{6 \mathrm{~h}}=0.461\right.$, $\left.t_{12 \mathrm{~h}}=0.617\right)$ indicated minor non-linearity due to possible adsorption processes. Nonetheless, it seems likely that adsorptive loss was not having a relevant impact on the investigated population but more data, for instance with other membrane material as laid out in the limitations, and more sophisticated methods to determine adsorption in RRT are desirable.

To summarize, we disagree with Honore et al. that a different conclusion should be drawn from our study, but agree that more research is necessary to inform about dosing of tigecycline in other, not yet investigated RRT settings.

\section{Abbreviations}

CRRT: Continuous renal replacement therapy; TGC: Tigecycline;

CWHDF: Continuous veno-venous hemodiafiltration; CWHD: Continuous veno-venous hemodialysis; CWH: Continuous veno-venous hemofiltration; IHD: Intermittent hemodialysis; RCA: Regional citrate anticoagulation;

UFH: Unfractionated heparin; HAM: Highly adsorptive membranes

\section{Acknowledgements}

None.

\section{Authors' contributions}

$\mathrm{PMH}, \mathrm{SR}$, and DDB designed the paper. All authors participated in drafting and reviewing. All authors read and approved the final version of the manuscript.

\section{Funding}

None.

Availability of data and materials

Not applicable.

Ethics approval and consent to participate

Not applicable.

\section{Consent for publication}

Not applicable.
Received: 20 January 2020 Accepted: 11 February 2020

Published online: 20 February 2020

\section{References}

1. Broeker A, Wicha SG, Dorn C, Kratzer A, Schleibinger M, Kees F, et al. Tigecycline in critically ill patients on continuous renal replacement therapy: a population pharmacokinetic study. Crit Care. 2018;22:341. https://doi.org/ 10.1186/s13054-018-2278-4.

2. Borsuk-De Moor A, Rypulak E, Potręć B, Piwowarczyk P, Borys M, Sysiak J, et al. Population pharmacokinetics of high-dose tigecycline in patients with sepsis or septic shock. Antimicrob Agents Chemother. 2018;62(4). https:// doi.org/10.1128/AAC.02273-17 Print 2018 Apr.

3. Dorn C, Kratzer A, Liebchen U, Schleibinger M, Murschhauser A, Schlossmann J, et al. Impact of experimental variables on the protein binding of tigecycline in human plasma as determined by ultrafiltration. J Pharm Sci. 2018;107:739-44.

4. Honoré PM, De Bels D, Spapen HD. An update on membranes and cartridges for extracorporeal blood purification in sepsis and septic shock. Curr Opin Crit Care. 2018 Dec;24(6):463-8. https://doi.org/10.1097/MCC. 0000000000000542

5. Tian Q, Gomersall CD, Ip M, Tan PE, Joynt GM, Choi GY. Adsorption of amikacin, a significant mechanism of elimination by hemofiltration. Antimicrob Agents Chemother 2008 Mar;52(3):1009-13. Epub 2007 Dec 17.

6. Sevillano D, Aguilar L, Alou L, Giménez MJ, González N, Torrico M, et al. Exposure-response analysis of tigecycline in pharmacodynamic simulations using different size inocula of target bacteria. Int J Antimicrob Agents. 2010; 36:137-44.

\section{Publisher's Note}

Springer Nature remains neutral with regard to jurisdictional claims in published maps and institutional affiliations. 